\title{
Integration of Design Safety into Curricula in the Undergraduate Programs: The Academician Perspective
}

\author{
Mohd Saidin Misnan*, Wan Faida Wan Azmi, Sarajul Fikri Mohamed, Zuhaili Mohamad Ramly, \\ Zakaria Mohd Yusof, Norazam Othman
}

Department of Quantity Surveying, Faculty of Built Environment, Universiti Teknologi Malaysia, Johor Bahru, Malaysia

Email: *b-saidin@utm.my

How to cite this paper: Misnan, M.S., Azmi, W.F.W., Mohamed, S.F., Ramly, Z.M., Yusof, Z.M. and Othman, N. (2017) Integration of Design Safety into Curricula in the Undergraduate Programs: The Academician Perspective. Open Journal of Safety Science and Technology, 7, 106-112. https://doi.org/10.4236/ojsst.2017.73010

Received: July 30, 2017

Accepted: August 27, 2017

Published: August 30, 2017

Copyright $\odot 2017$ by authors and Scientific Research Publishing Inc. This work is licensed under the Creative Commons Attribution International License (CC BY 4.0).

http://creativecommons.org/licenses/by/4.0/

\begin{abstract}
The current and growing construction industry in the country has led to increasing of accidents related to construction workers. In an attempt to decrease accidents on site, the design safety concept is the most suitable measures to date. Though the impact is evident and potential benefits of its implementation are apparent, widespread application of this intervention in the Malaysia's construction industry is currently lacking especially in the academic sector. Therefore, this paper aims to explore the integration of safety and health to the current curricula focusing on the engineering programmes and their perceptions towards design safety concept and its implementation. The types of design disciplines included in the research study were limited to academicians. A total of 72 respondents received via questionnaire and the responses were scored on a 5-point Likert Scale to express their level of agreement. The results show that the graduates are not equipped with adequate knowledge of safety and health legislation and regulations through the current curricula and disagree that the content of the programmes is adequate. Although majority agree on the positive effect of design safety towards accidents on site, there is still minority who believe that the concept has no significant effect towards site safety. However, this paper concludes that there is no major impediment from the academic sector on the implementation and integration of design safety concept to the undergraduate curricula. The implementation of design safety should be in a well organized structure for effective results towards zeroaccident as well as increases the designers' value in the construction industry.
\end{abstract}

\section{Keywords}

Safety Integration, Undergraduate Curricula, Academic Perspective 


\section{Introduction}

In regards to the Malaysia's Master Plan for Occupational Safety and Health in Construction Industry 2005-2010 [1], it has stated their plan to proposed a new regulation based on Construction (Design and Management) Regulations under DOSH by the year of 2006. CDM Regulations placed a certain specific duties directly on designer to eliminate hazards where feasible to reduce risks from those hazards that cannot be eliminated and to provide information on residual risks if they are significant. In other words, CDM Regulations implemented the design safety concept to the construction industry. However, up until today, there is no sign of an integration of this concept to the Malaysia's construction industry. This may be caused by limited research done on design safety concept in this country. Hence, this paper discussed on the results gained on the current integration of safety and health curricula and the perception and awareness on the concept by the academician. It is organized as follows. In Section 2 touching on the Design for Construction Safety concept while Section 3 explains on the Design Safety Education (DSE).

\section{Design for Construction Safety (DfCS)}

Design for Construction Safety (DfCS) is a process where it influence design decisions of a permanent building, facility or structure to eliminate, mitigate or reduce the need of personal protective equipment such as fall protection both during construction phase and maintenance [2]. The implementation of design safety concept in the construction industry may be successful by improving the education of the designers by incorporating into the curricula [3] and increasing awareness of the academicians and professionals [4].

In order to perform this concept successfully, the designers are required to retain a solid understanding of occupational health and safety to be able to incorporate this into their design [5]. Understanding the concept and application of the Occupational Health and Safety management system, requirements, responsibilities and penalties are very important to prevent accidents, ill health and injury at workplaces towards development of safety culture while benefits the organizations with on their health and safety investment [6]. Besides knowledge on Occupational Health and Safety, designers are required to equipped with knowledge of workplace hazards and their harmful effects, understand the risk management process, the principles of designing to minimize human error and awareness on how design can impact on reliability, safety and unwanted capabilities [7].

\section{Design Safety Education (DSE)}

The initial step in accomplishing this is through the interference of the accreditation board [8]. In Malaysia, the board of Architect is responsible for the accreditation of architect programme formed under the provisions of the Architects Acts 1967 and empowered the Council of Architectural Education Malaysia 
(CAEM) to regulate all matters relating architectural studies. For the programmes in Civil Engineering, the Board of Engineers (BEM) has a duty to ensure that the quality of engineering education programme attains the minimum standard comparable to global practice by delegating Engineering Accreditation Council (EAC) for accreditation of engineering degrees. However, the current requirement skills under these accreditation boards does not include the health and safety subject therefore, both the architecture and engineering did not make an effort to include it as a primary course in the universities [9].

The universities rely on the accreditation bodies to gain public recognition of the courses offered which may resulting in merely compromising important skills required by the profession in order to satisfy the demanding university curriculum requirement. These lead to the second proposal by the MPOSH to make it as a requirement or regulations by the accreditation board to integrate Occupational Safety and Health content into all undergraduate curriculums especially in engineering, architecture, surveying and other related courses [1]. Instilling safety skills to the designers does not turned them into a safety engineer however it increases their value as a professionals [9]. This is one of the approaches that may change the practicing culture into considering the safety of the construction workers in their designs. The academic community has a lead role to play in supporting and ensuring the enhancements of the knowledge provided to the students to convert the knowledge into practicing culture [10]. A pilot study was taken place in ordered to evaluate the sufficiency of the safety education in the context of construction worker's safety and the respondents' view on Design for Construction Safety concept. The results are expected due to the fact that the accreditation bodies and universities has minimal requirement on safety and health in regards to the construction site. The researched found that the main barrier for the implementation is the lack of information and education on safety method [11].

The emphasis of design safety concept in the curricula can helps to improve the poor safety record of the construction industry. One of the approaches that may be effective is by integrating it into the existing courses through case studies and outlining problems faced by real designers so that they are able to transform the knowledge and apply during practicing [12].

\section{Research Questions}

There are plenty of studies researched on design safety concept including the intervention, implementation, tools, impacts, solutions and results in implementation. However, only few studies touched on the implementation and intervention of this concept. The viability of the design safety concept must consider the factors that impacting the implementation and the impact resulting from the implementation [2]. An implementation of the concept is considered viable only if the factors impacting the implementation do not prohibit its implementation and the outcomes of the implementation are beneficial that they provide motiva- 
tion to implement the concept. In order to access the viability of the concept, the designer's knowledge and current education system is viable to be explored in order to evaluate the gap between the current practice and current offerings in the academic system. This paper's research questions are:

1) What is the practice of health and safety integration in the current curriculum?

2) How the current health and safety is being integrated into the undergraduate engineering program?

3) What is the perception and acceptance level of design safety concept by the academician?

\section{Data Collection and Preparation}

The types of design disciplines included in the research study were limited to academicians. Through the use of a survey, respondents were asked to answers three sections. Section A was designed to capture personal data about the following variables, expertise, years of experience and academic role. These variables were considered to be possible independent variables that influenced the academicians' perception on design safety. Section B was designed to capture on the current health and safety integration in the undergraduate programmes. Section $\mathrm{C}$ focussed on the academicians' perception and awareness on this concept. The survey was distributed by using the online survey tool Google Forms, by hand and by airmail. All identifying information from participants was stripped from the responses prior to data analysis. The data were analysed using SPSS computer program.

The respondents had varied backgrounds representing a variety of expertise, durations of work experience and their role in the academic position. Of those 72 respondents, $38.9 \%$ are under the civil engineering program, $29.2 \%$ are under the architecture program and $31.9 \%$ for construction program. The majority of the respondents (59.7\%) have more than 10 years experience in the academic sector. The respondents consist of $\mathrm{n}=21$ lecturer, $\mathrm{n}=23$ senior lecturer, $\mathrm{n}=8$ head of department, $\mathrm{n}=9$ associate professor, $\mathrm{n}=11$ professor.

\section{Result}

\subsection{Current Health and Safety Integration}

The mean score for current education culture among academicians was 2.43. This below average value indicates that academicians mostly do not agree that their current lectures or teaching system involved design safety concept. Based on Table 1, the result shows that the adequacy of health and safety content in the current curricula is low (2.5972) that leads to graduates with low knowledge on the construction legislations and regulations (2.6389). Despite minimal integration on safety and health in the curricula, the academician makes an effort to instill their students to the importance to consider safety and health during designing (3.7222). 
Table 1. Current health and safety integration.

\begin{tabular}{cc}
\hline \multicolumn{1}{c}{ Statements } & Mean (Sd) \\
\hline $\begin{array}{c}\text { Our graduates are equipped with adequate knowledge of } \\
\text { health and safety legislation and construction regulations }\end{array}$ & $2.6389(1.06554)$ \\
$\begin{array}{c}\text { Our undergraduate programmes provide an opportunity to } \\
\text { develop understanding of health and safety }\end{array}$ & $3.2361(0.98572)$ \\
$\quad$ Our health and safety content of \\
undergraduate programmes is adequate \\
$\begin{array}{l}\text { Our students are informed that it is very important to } \\
\text { consider safety and health towards the } \\
\text { construction site safety during designing }\end{array}$ & $2.5972(0.86659)$ \\
\hline
\end{tabular}

The variable was analysed using ANOVA to identify if there any statistically significance difference among the expertise, years of experience and role. There was no statistically significant different between groups of expertise $(\mathrm{F}(2,72)=$ $1.575, \mathrm{p}=0.214)$, years of experience $(\mathrm{F}(4,72)=0.406, \mathrm{p}=0.804)$ and academic role $(\mathrm{F}(4,72)=0.309, \mathrm{p}=.871)$ as the significant value is $\mathrm{p}>0.050$.

The extents to which the academicians are currently integrating design for construction safety concept are examined. The respondents were asked "How the current health and safety is being integrated into the undergraduate engineering program?". From 72 respondents, three respondents stated that their department strongly encourages site visits to construction sites in the purpose of deepen their safety knowledge in terms of identifying the potential hazards and unsafe acts commonly occur in construction site. Whereas, 19 respondents listed out subjects where safety topic is applied Construction Project Management (11), Construction Technology (4), Engineering Management (4), Professional practice (4), Occupational health and Safety (3), Legal studies (1) and Principles of measurement (1). Two respondents stated that there is no input of safety design in their current curricula while the other respondents have no response on the questions.

\subsection{Perception and Acceptance of Concept}

The academicians were asked on their perception of the impact of design safety concept. When asked whether by instilling design safety, will the rate of accidents in Malaysia minimize? Majority of the respondents (76.4\%) agreed on the effect of the integration of design safety towards minimizing the rate of construction accidents. In response to the question "Should the Accreditation board establish an accreditation requirement on the need of design safety in the curriculum?" majority of the respondents (72.2\%) agreed while others disagreed. The comments stated by these respondents are that the current accreditation is sufficient therefore it is not necessary for this addition. Above that, one respondents stated that awareness towards the designers will not have much effect to site safety as the actual works is done by the contractors therefore it is more relevant that the contractors attends safety education. This result is in line with responses 
received in a past research that stated site safety is completely under the control and responsibility of the contractor.

The result shows that eight respondents agreed on the effects of design safety towards minimizing site accidents however disagree on the integration of the concept in the undergraduate programme. They suggest that design safety to be included in the current subject as one of the topic or offered as an elective subject. The respondents felt that the current curriculum is already packed with more important engineering subject therefore additional subject will burden the students. In addition to that, one of the respondents stressed that the implementation should only be in action when there is adequate experts on this concept while another stated that even if it taught during their formal education, it is an individual awareness to apply the concept during practicing.

The result also shows that seven respondents disagree on the effect of design safety towards accidents but agree on the implementation through the accreditation board. Contradicts with the earlier reasons, these respondents felt that although they don't see the relation between design safety and site accidents, they feel that additional knowledge on safety is important for the students and future designers. This knowledge may increase their awareness and therefore lead to consideration to take serious measures when it comes to risks and hazards during designing stage.

\section{Conclusions}

This paper reveals to which extent the safety and health awareness is fostered during the undergraduate program. Identifying the level of awareness is important in order to identify the adequacy of the current curricula in terms of design safety. Safety awareness cultivated in the early stages of learning is the first of many steps in order to proceed with the implementation of design safety to the construction industry by intervention through engineering curriculum. The current curricula have minimal intervention on design safety however the academician makes an effort to instil the importance of safety and health to their students. This paper concludes that there is no major impediment from the academic sector on the implementation and integration of design safety concept to the undergraduate curricula as similar to the acceptance of the concept on behalf the engineers' perspective based on past research. However, the integration should be in a well organized structure and not in haste to ensure effective results.

This paper suggests that in order to promote the integration of safety and health into the current curricula, the first step is to produce a well-organized implementation framework. An implementation framework with stage appropriate activities is necessary for a successful new practices or change. This framework may include factors affecting the implementation, processes and results of implementation. With the use of the framework, cooperation between all parties; government bodies, accreditation board, universities, academicians and 
professionals, are important for a smooth and successful integration.

\section{Acknowledgements}

This work was supported in part by UTM Zamalah Scholarship.

\section{References}

[1] Construction Industry Development Board, Malaysia (CIDB) (2006) Master Plan for Occupational Safety and Health in Construction Industry 2005-2010. Construction Industry Development Board, Kuala Lumpur.

[2] Gambatese, J.A., Behm, M. and Hinze, J.W. (2005) Viability of Designing for Construction Worker Safety. Journal of Construction Engineering and Management, 131, 1029-1036. https://doi.org/10.1061/(ASCE)0733-9364(2005)131:9(1029)

[3] Ayalp, G.G. and Öcal, M.E. (2016) Determining Construction Management Education Qualifications and the Effects of Construction Management Education Deficiencies on Turkish Construction. Creative Education, 7, 254-268.

https://doi.org/10.4236/ce.2016.72024

[4] Australian Safety and Compensation Council (ASCC) (2006) Safe Design Engineering Students: An Educational Resource for Undergraduate Engineering Students. Australian Government.

[5] Abbas Abbas, R., Mohamed Zalat, M. and Salah Eldeen Ghareeb, N. (2013) Non-Fatal Occupational Injuries and Safety Climate: A Cross-Sectional Study of Construction Building Workers in Mit-Ghamr City, Dakahlia Governorate, Egypt. Open Journal of Safety Science and Technology, 3, 69-79.

https://doi.org/10.4236/ojsst.2013.34009

[6] ElSafty, A., ElSafty, A. and Malek, M. (2012) Construction Safety and Occupational Health Education in Egypt, the EU, and US Firms. Open Journal of Civil Engineering, 2, 174-182.

[7] Silva, S., Araújo, A., Costa, D. and Meliá, J.L. (2013) Safety Climates in Construction Industry: Understanding the Role of Construction Sites and Workgroups, Open Journal of Safety Science and Technology, 3, 80-86. https://doi.org/10.4236/ojsst.2013.34010

[8] Azmi, W.F.W. and Misnan, M.S. (2013) A Case for the Introduction of Designers' Safety Education (DSE) for Architects and Civil Engineers. Advanced Engineering Forum, 10, 160-164. https://doi.org/10.4028/www.scientific.net/AEF.10.160

[9] Azmi, W.F.W. and Misnan, M.S. (2013) Designer's Safety Curricula for Undergraduate Students. American International Journal of Contemporary Research, 3, $115-121$.

[10] Teck, A.G.P., Asmoni, M.N.A.M., Misnan, M.S., Jaafar, M.N. and Mei, J.L.Y. (2015) A Review on The Effectiveness of Safety Training Methods for Malaysia Construction Industry. Jurnal Teknologi, 74, 9-13.

[11] Teck, A.G.P., Asmoni, M., Hamid, H.A., Misnan, M.S. and Lee, J.Y.M (2015) Evaluation Criteria of Safety and Health Induction for Construction Worker (SICW) in Malaysia, Jurnal Teknologi, 73, 93-97.

[12] Misnan, M.S., Mohamad, S.F., Yusof, Z.M. and Bakri, A. (2010) Improving Construction Industry Safety Standard through Audit: SHASSIC Assessment Tools for Safety. Proceedings of the CRIOCM 2010 15th International Symposium, 6-7 August 2010, Johor Bahru, 548-556. 
Submit or recommend next manuscript to SCIRP and we will provide best service for you:

Accepting pre-submission inquiries through Email, Facebook, LinkedIn, Twitter, etc. A wide selection of journals (inclusive of 9 subjects, more than 200 journals)

Providing 24-hour high-quality service

User-friendly online submission system

Fair and swift peer-review system

Efficient typesetting and proofreading procedure

Display of the result of downloads and visits, as well as the number of cited articles Maximum dissemination of your research work

Submit your manuscript at: http://papersubmission.scirp.org/

Or contact ojsst@scirp.org 